Chapter keywords: artist, dancers, gesture, improvisation, interpretation, intersemiotic, performance, process, translation.

Movement as Translation: Dancers in Dialogue

Ella McCartney

A street performer sprints between two junctions in SoHo. Between movements he stands still and positions himself in a series of recognisable poses. His hands hold his waist and his back is straight; his eyes look past the audience. Standing still, one foot crossing the other, his arms are held high with his palms facing out. My interpretation of his movements unravels over time. What I thought had been re-enactments of Michael Jackson posters collapses, and instead I realise they had just been resting points between bouts of sprinting.

This initial (mis)interpretation was the starting point for a new work, which forms the basis of the present exploration of translation, collaboration and process. After selecting a series of Michael Jackson posters, I started to work with two dancers, Amy Harris and Ruby Embley. Looking at the six posters, we began to reinterpret the poses in the images into movements. I invited the dancers to work on a translation of the images with me, and we each took an active role in the process. We worked together as three individuals who brought with us different bodies, experiences and disciplines. This text will bring forward the unique perspectives of the dancers in the transcribed conversation below.

At the time of making the piece I was working as Artist in Residence in the Department of Applied Linguistics and Communication at Birkbeck, University of London. A focus of the research during my residency was translanguaging, which is described by Li Wei as "going between different linguistic structures and systems and going beyond them" $(2011,1222)$. I chose to work with performance and choreography as a method to explore improvisation and interpretation and how these are utilised in communication. At the end of the residency, I presented a solo exhibition in London entitled, To Act To Know To Be, a phrase used by Ofelia Garcia and Li Wei in Translanguaging, Language, Bilingualism and Education (Garcia \& Wei, 2014: 137). The dance piece performed by Amy Harris and Ruby Embley was included as part of the exhibition, which was the last staging of three performances in total. The performance was also presented at Nottingham Contemporary and at University College London.

This paper is a continuation of our process and via this written account another form of translation is taking place. It is vital that I do not speak for the dancers but that their voices are included in this account. The conversation provides an insight into our process and the experiences of the dancers, and describes how we transformed and translated the static images, through their bodies, into movements. The piece performed by Amy Harris and Ruby Embley was the result of a polyphonic process. The work, or "living utterance", to borrow a phrase from Bakhtin (1981: 276), is connected to the context in which it is produced as well as simultaneously being part of an ongoing dialogue with past and future contexts. The interconnected relationships between these contexts are not limited or confined to one system or mode, but are inevitably transmutable and intersemiotic.

Our process included multiple modes of communication that were used simultaneously, including verbal discussion and physical movement. Despite the dancers both having trained in the same institution, they brought very different approaches to the rehearsal 
process - and these differences enriched the outcome. I have received no formal training in choreography or dance specifically; my own background is in fine art. The vocabulary that we each used varied and required us to negotiate the process together without knowing the final outcome. The methods that would be used to adapt the material formed a core aspect of the work, so I intentionally did not ask the dancers to repeat a set piece of choreography as devised by me but invited them to work with me collaboratively. Translanguaging, as discussed by Garcia and Li Wei, after all, "makes visible the different histories, identities, heritages and ideologies of multilingual language users" (Garcia and Li Wei, 2014: 137).

My intention was to open up the process and explore how we could translate the material into a different form, one that had duration and would be presented live in front of an audience. Each staging of the performance lasted approximately seven minutes and included a weave of six different poses, partly improvised, in various combinations and sequences, which enabled new dynamics to emerge. The poses were performed by each of the dancers differently, partly due to their individual reinterpretations of the images in the translation process and partly to the mannerisms they each brought through their anatomy. For example, the angles in which they held their arms, their speeds travelling through the poses, as well as their individual gestures as they moved through the piece, were all expressed distinctly. As the emphasis was placed on the process of reworking of the material, I took the decision for the dancers to continue to wear their rehearsal clothing instead of homogenising costumes for the final performances. The movements became a live conversation between the dancers, improvising and responding to each other and to the environment.

The performance was presented in three different contexts, which inevitably impacted how the various poses could be interpreted. The first venue was a neo-classical central portico at University College London that was completed by William Wilkins in c.1827. The Corinthian columns frame the structure at a scale that dwarfs the human height. A number of the poses, when seen in this context, could appear to echo classical poses represented in sculptural works such as Ilissos ${ }^{1}$. In turn, poses seen in classical sculpture may have had an influence on poses adopted in contemporary choreography, including those performed by Michael Jackson.

The second staging was held in a purpose-built performance space at Nottingham Contemporary. In contrast to the portico, the room was dark with one central spotlight focused on the area of the performance and also included sound. The audio was amplified on speakers inside of the performance space but had been manipulated using filtering techniques to produce the effect of it moving from outside to inside the room. At first the audio was muffled and distant but gradually increased in volume and clarity. As frequencies slowly filtered into the space, details of the audio became increasingly present and had the effect of being in close proximity to the audience.

The final performance took place as part of my solo exhibition, "To Act, To Know, To Be", at Lychee One Gallery in East London. The entire room became a platform for the performance, which intentionally destabilised the boundaries between viewer and performer. Light was evenly balanced across the space, equally illuminating the dancers and the audience. Due to the limited scale of the room, viewers stood in and amid the performance in close proximity. The bodies of the audience thus became an extension of the work, vulnerable and consciously being looked at.

As the dancers began to learn and embody each pose or phrase ${ }^{2}$, they began to perform each move with their own unique accents. I wanted to incorporate this aspect of the process in the final piece, to show how the poses had been learned and then entirely 
embodied. The structure of the piece started with the dancers articulating (nonverbally) and describing each pose through their bodies. The precision and pace of their movements at the start of the piece was as if they were instructing the audience about each element of the vocabulary. The tempo of the movements started slowly then increased in momentum, fluidity and fluency. The last phase was performed at a rapid pace, without pausing at each pose. This structure aimed to reflect the process of learning a new language, starting perhaps with set phrases and then moving towards dynamic communication that is expressed fluently.

The present enquiry does not aim to examine the "faithfulness" of the final movements in relation to the 'original material' (Phelan 1996:39). Instead, the focus is placed on the process of the translation, which was also what I prioritised during the making of the work, over and above the end result. Some of the ethical implications are explored further in the conversation below. The dancers are not material objects, they are people, and they performed and embodied the translation.

The complexity of identity touched upon in the interview opens up much wider notions of the internal and internalised experience of the performer in relation to embodiment, and ways in which meaning is connected to and performed by one's own body, context and identity (Butler 1988). Alongside many other factors, the interpretation of the poses is linked to the bodies that perform them. We cannot isolate the pose from the body. From the perspective of the dancer, her internalised experience of embodying the pose is bound within the context of her own (female) body as well as via an awareness of the socially constructed ideas of gender. From the perspective of both dancers, their bodies generated a different set of associations of the pose, one that they interpreted to be a differently gendered pose, as acted out by Jackson.

My initial idea for the piece was to explore the process of transforming a series of static poses into a live performance and to consciously think of this as a form of translation. I was not interested in mimicking the poses in the posters exactly, or for the performers to imitate Jackson. During the interview with the dancers as transcribed below, I became aware of the dancers' own perceptions of how their bodies impacted upon the poses.

By hearing the voices of the dancers, I hope that a shift in perspective may become possible: from the focus being on the experience of the viewer to the experience of the performer.

I have decided not to include a conclusion and to leave the transcript of our discussion as the main content of this text.

\section{Interview 2017}

Artist/interviewer Ella McCartney (EM)

Dancers: Amy Harris (AH) and Ruby Embley (RE)

EM: Shall we describe the process of making the work? How we started by looking at the Michael Jackson posters and how we translated these into live movements? 
RE: I remember us having a couple of funny moments when we tried to work them into our bodies and they became something very different. As young women they become something slightly provocative.

$\mathrm{AH}$ : The one where he is lying on the floor in the reclining position.

AH: It's funny how that changes on our bodies.

RE: We scrapped a few straight away because they didn't work, for that reason.

EM: Do you think those images were provocative when Michael Jackson performed them?

AH: No, I don't feel like they are necessarily provocative in themselves.

RE: No, I don't think so either.

AH: They just exude his style and his symbolism.

RE: Maybe it would be interesting if we could play with them and see if we could desexualise them. Or in the context it wouldn't come across that way.

$\mathrm{AH}$ : But with that pose where he is reclining and like you said it was quite masculine, we actually did it and it is typical, for a man that is totally fine-he can just bare his crotch and can feel really proud. For a woman that's very different.

EM: The pose lying down was quite confrontational when you performed it; you made direct eye contact with the audience. Did that change your relationship with the viewer?

AH: I feel like it relates to those power poses. Certain poses not only boost your feeling of confidence but can give the impression of dominance as well. As the poses are so typically male, it is probably very effective that we then put those onto ourselves and took on a dominant posture. The fact that we were imitating a male as well-it came from Michael Jackson-is interesting.

RE: So often his legs are crossed or turned in as well. It's quite unusual that he does sit with his legs turned out. As you said, on his body when he has his legs turned in it doesn't look coy or overtly sexual.

EM: There was something in the way you performed those poses in a confrontational way that I quite enjoyed; almost intimidating for the audience.

AH: I would slide into the pose, because of that sweeping movement that would take me right to the edge of the audience, to then lie in that pose.

EM: All the movements in our performance had been derived from posters of very defined poses. Can you say something about the process of translating an image into a movement and how much room for interpretation there was?

RE: We started by improvising; we had selected poses and then played around with putting them together. We were playing with different levels.

AH: I remember us having a conversation with you, introducing you to the fact that we were very comfortable to improvise with it and to have decided these set statue points 
throughout but then for us to at first have the liberty to play with speeds and dynamics and textures and our body and to try and find different ways to travel between them.

EM: We started with an image of Michael Jackson which we then re-interpreted or translated into a movement, onto your own bodies. Was there an instance when you both translated or interpreted the image differently?

RE: Because they were quite set-posters into poses-it was very easy to translate them exactly. The positions that we both had were the same but the way we moved between them changed.

I remember us having a long conversation about the idea of flourishes or decoration and whether we needed them or not, whether they distracted from the final pose.

EM: That's interesting as the decorative aspects were not elements that were set from the beginning. If we think of it as a process of translation, those parts were not explicitly there in the original text.

RE: We discussed if they came out naturally out of fluency, or whether it was something that we were adding in that came naturally to us but was nothing to do with the positions in the posters.

AH: More productions of habit.

EM: What do you think they add?

AH: You do get into a habit of your way of talking, I guess, your way of moving your body. You build habits. Its like how I have habits in how I speak verbally, as dancers we have that and as humans in general we have that in our bodies too. It's very hard not to bring that, particularly in improvisation where you have to make instantaneous decisions. It's difficult to have so much cognitive awareness of everything that all of your body is doing, unless you have taken the time to learn a phrasing and learn the placement of every part of your body. Would you agree?

RE: I think so yes. But even in parts of the improvisation, there was a difference between what we did in the first performance at Nottingham Contemporary and what we did as the third performance at Lychee One Gallery.

AH: I remember that being a conscious decision. The way that you directed the progression of the piece for Nottingham Contemporary informed how you changed it for the gallery because for both the University College London and the Nottingham Contemporary performances we decided to build a shift in dynamic throughout, and because we build up in speed and fluidity of movement, and fluency too-building on the speed and fluidity built the fluency3. By doing that we slipped out of the stationary nature of the poses. It really embodied this fluidity and fluency that comes with spoken language as you learn it. That also works for the context of the performances.

RE: If you are thinking of it like learning a language, the more fluent you become, the more you start to play and I think that is when the flourishes come in.

AH: Like the accents. 
EM: Perhaps it demonstrates how you were facilitating your own resources that you have built up through your own experiences, histories, training; you create additions to the original material or start to adapt it.

I wanted the audience to connect the poses in the performance to the posters without limiting other possible interpretations. In the performances that did not have audio, did the movements communicate the original material more directly?

RE: There's also something about the music that changes the way we perform the movement, it adds a drama and pizazz to it, and I think that changes the way you read the poses as well. It becomes a lot more theatrical whereas without music it is just bodies in space. For me it made me add flourishes and dynamic impacts.

EM: It is also interesting to think about context; the first performance in the Portico was without audio and was positioned in a neo-classical building. The interpretations of the poses were different as a result. In Nottingham Contemporary it was performed in a more traditional performance space with spotlights. The audience was quite distant. The relationship between your bodies and the bodies of the audience felt more separated. The final performance in the gallery space was presented alongside art objects and you had a much closer proximity to the audience.

Describe the starting process, from looking at the images to then transferring that onto your body into movements. As the images included the human body did your process involve mimicking the poses to some extent on to your own body?

AH: It reminds me how much learning dance and choreography relies on mimicking. It is so visual. Ninety eight per cent of the time we learn from watching another body and copying it, or watching a video and copying it. Or seeing the photos and mimicking those rather than some other form, which would be interpreted very differently, like someone verbally instructing "put your right leg there...". I wonder how different it would look if you had explained the poses through words, rather than us looking at the images and copying them?

EM: When you are learning a new dance from another body, how much room is there for different interpretations?

RE: Bodies are different; some people will have more strength or flexibility in different places. I think when you are first learning something, people will pick up on different things-some people are more observant than others, so one person might get the shapes exactly right but the dynamics slightly wrong.

$\mathrm{AH}$ : It depends on the style where the values are put. Some styles put value on you copying it to a T. For example for a corps de ballet with a group of twenty or something, their value is to have perfect unison and to not notice any difference, just to see a mass of one. The value there is to be very precise and to be identical. Whereas other teachers might value a sense of flow-they won't be looking for you to match the movements of their anatomy but the movements of their dynamic.

RE: Some teachers will value individuality. They will teach you a phrase and what they are looking for is for you to reinterpret that yourself. The mechanics and fundamentals of movement will hopefully still be the same-depending on how well people have learnt it. I also think when you are learning something, depending on what your background is, your priority will be different. Different people will pick up on different things. 
EM: This is something I have been interested in during the project: the differences individuals bring in relation to their own histories, experiences, training or anatomy...

RE: We have had the same training at the same school but had different experiences. I think we do move differently.

AH: Without a doubt, you can sense personalities through their movement when you are watching them.

EM: Were there any details or specific parts of the images that we felt we couldn't lose because we felt they were key? Was there anything in the images that was present in the last performance that didn't shift throughout or get transformed?

RE: I felt that the poses were quite set and true to the images, but I might be wrong. We had a long conversation about the placement of the hand and if it should be on the hat rim or head.

$\mathrm{AH}$ : At one point you were doing it on your head, then Ella said "why is Amy putting her hand there?" I said because (Michael Jackson) is holding his hat. So that is an example of when we can get carried away with moving, or our habit, or assuming something.

EM: There is a pose used in our performance where you move with one arm behind your back. I think we developed it through the rehearsal process, as I can't find the poster that it derives from.

AH: We did adapt that-I remember doing it first and his hands are in quite a structural position. I think it was too vague in the context of our dance when we were trying to make strong stills in order to juxtapose the movement. It might have looked stronger from the outside to have a curve than the risk of, mid dance, the hand just hanging.

EM: So that was an adapted pose. I wonder if that uses a combination of different reference points instead?

AH: Ruby—you said you had just come from doing a performance about Greek statues.

RE: We had a conversation about how we felt in ourselves, and if we felt like Michael Jackson or if these are just positions, or how you break those two things up when you are performing it. That changed when the music started.

EM: I wasn't so aware of that. During the process were you thinking of the images more as a shape or embodying him as a performer?

RE: That was the big difference between performing it with the music. Without the music in the portico space at UCL, it is very removed from him and the music. They do feel like positions of your body, or classical images. The setting in Nottingham Contemporary felt different.

EM: Everything felt more theatrical with the spotlights and the audio, which was emotionally manipulative.

RE: Yes, and the temptation is to play up to that with your movement.

$\mathrm{AH}$ : The audio was quite surging and serious. 
EM: The audio builds up and the volume increases.

I was also thinking of the poses and their context. I think a lot of the original Michael Jackson choreography probably adapts and mimics poses from elsewhere. So the movements are already translated to an extent.

That connects to my selection of which of the posters to use. He is so iconic; the poses almost go beyond him as an individual and become something else. That was part of my attraction to using those specific poses, as well as being recognisable so that the traces of the movement can be recalled. The final piece was able to be quite loose and abstract whilst still having a connection to the poses in the posters.

Could you say something about gender and your experiences in relation to this during the process of making the piece? I wanted the performance to avoid or to go beyond the idea of you both being things to look at. It was more about what you bring to the collaboration as performers and individuals throughout the entire process. We have spoken about the poses in the posters being slightly provocative or macho and how that might be transferred or changed when acted out by a female body. I wanted the process to be collaboration between us all and not for me to take the role of directing or instructing everything. Were these things present in the process for you?

AH: For me it's a big question and a big thing that I am starting to deal with but only just scratching the surface; this dichotomy of moving and being spectated or moving and being witnessed or that there are different purposes to allowing viewers to see what my body is doing. It's a big question, and I often think of it from a feminist slant as well as how my body is always being viewed, and women's bodies as objects for viewing and that it is something that takes your power away from you. It's not giving willingly; it's just done to you from a young age. Becoming more conscious of that has made me become more conscious of it in my performance too and I want to find more ways to own my body and its movements and its being, and to want to offer those myself and give those myself because I am choosing to do that, not because that privilege is just given to you or that it is taken from me. It is something that I think about a lot and something that I am trying to think about in this process too.

EM: Is that something that you are generally aware of during the rehearsal process in relation to the director or choreographer, or is it something that takes place in the live performance with the audience, or both?

RE: One feeds into the other I would say. If you feel like you have had agency in the process then when you go out on stage you are much more likely to feel powerful and like you have ownership over what you do.

The different (performance spaces) really changed how I felt about whether I was being viewed as an object or whether I was choosing to be seen or whether it was just happening. The thing you were saying about having the audience at a distance-you have a very marked out space that is yours and that makes a huge difference to how in control you feel. That is a very different style of performance and one we are quite used to, but as soon as we went into the gallery, people were very close and the space is no longer yours and you are in a space with other objects that are there to be viewedthen it became something quite different. I think it is a really interesting style of performance and not one to shy away from just because it makes you feel less in control. I think there is an interesting question about how do you maintain your sense of ownership and power when the audience are that close. There is also the thing of being audience and then becoming performer and how you go back to being audience again 
and I felt how strange that made me feel when we were doing it, and that was really interesting and something that we should play with more.

$\mathrm{AH}$ : I felt quite different actually. For me the more intimate space of the gallery gave me more agency and playfulness and I enjoyed that context more. It feels more playful, whereas the more traditional stance of "I'm here and you're there and you're there to sit and watch me do this"-I feel like that has more pressure around it and that's where I'm personally trying to work harder to find more freedom in that situation and to not have a negative association with all of the gaze on me, looking down on me, but to have a more positive association with it and to own and enjoy my power in that space. It is a very powerful space where I can present a version of myself, but it is up to me and that's actually an amazing opportunity of what I want to give and they are there to receive it. I'm trying to work on that way of thinking about it as opposed to the other way.

EM: As someone in the audience watching both of the performances, my experience was that in the Nottingham Contemporary space it felt as though the audience were more passive. They were physically in the dark and you were both lit up; they felt more distanced from the situation

RE: You could almost forget that they were there.

EM: In the gallery space, it was a space where everything was being looked at-that included the audience. [From my experience] the audience was made to feel selfconscious or self-aware. It was also the timing of the performance disrupting the space; the audience were inside the gallery and the performance began unannounced-at that point the audience were not fully in control about where they were positioned in the gallery. Because it was in the round, everyone was then looking at everyone else. The audience became part of the performance. You were both physically closer to the audience, which was something potentially quite intimidating for them. In both performances you seemed empowered but in the gallery space the audience had to be active-having to change where they were in the space or change how their bodies were positioned. It felt as though everyone was being looked at-which was interesting. I know for sure that my approach to working in this way is different from how I think about and worked with the rest of the exhibition.

AH: I think that is why I find it playful, and like you said, there is a certain power in the gallery setting. I'm interested in reciprocated performance. If I am there I am offering something, I'm actively doing something-how are you [the audience] going to engage with it and how will you reciprocate something back? And then for the audience to have to be more on their toes, managing the space as well as you are-it feels right, to me at least. We are all engaged in this thing-and that engagement is really important to me.

EM: Neither of the performances had a stage or platform; there was no physical separation between you and the audience. We were all in that same space.

AH: That kind of goes back to the fact that it was a live body that spoke to you in providing the inspiration-it wasn't the flat images that you thought would be important for a live space, it was actually a body dancing and creating those images and associations for you.

EM: Yes, the way that this piece came about was that I saw a street performer in New York and thought he was performing poses from Michael Jackson posters, but after a while I realised that was not what he was doing at all. The idea stemmed from my initial misinterpretation of a live performance. 
References

Bakhtin, M. M., and Michael Holquist. 1981. The dialogic imagination: four essays. Austin: University of Texas Press.

Butler, Judith. 1988. "Performative acts and gender constitution: an essay in phenomenology and feminist theory." Theatre Journal 40 (4):519-531. doi: $10.2307 / 3207893$.

Garcia, O. and L. Wei. 2014. Translanguaging, language, bilingualism and education. London: Palgrave Macmillan

L.Wei. 2011. Moment analysis and translanguaging space: discursive construction of identities by multilingual Chinese youth in Britain. Journal of Pagmatics 43 (5), 12221235

Phelan, James. 1996. Narrative as rhetoric : technique, audiences, ethics, ideology. Columbus, Ohio: Ohio State University Press.

${ }^{1}$ A statue from the West pediment of the Parthenon (438BC-432BC) held as part of the collection at the British Museum.

2 Throughout the text I have intentionally used terms that relate to both dance movements and speech. Here 'phrase' is used to describe the sequence of movements that form each pose. Throughout the process the sequences were continually modified which built up a vocabulary of phrases.

${ }^{3}$ In this context the term 'Fluency' refers to the flow of movement. 